\title{
Arqueología en un paisaje agrario La planificación del Proyecto Otínar
}

\author{
Marcelo Castro López * \\ Narciso Zafra de la Torre * \\ Francisca Hornos Mata *
}

El proyecto Otíñar persigue la recuperación de un espacio extenso de la Sierra de Jaén, que coincide con los límites actuales del señorío de Otínar. El proyecto se propone abordar la investigación arqueológica de una comunidad agraria y su territorio, comprobar la validez de ciertos métodos y conceptos de la disciplina arqueológica, y examinar el estado de conservación y las posibilidades de musealización de un conjunto disperso de elementos patrimoniales localizados en su ámbito de actuación.

Trascendiendo estos intereses normales de la investigación arqueológica, el proyecto también tiene el propósito explícito de contribuir de manera efectiva a la formulación y desarrollo de nuevas estrategias de apropiación de este territorio marginal. Estas estrategias se encuentran encaminadas en general a promover nuevas relaciones sociales y económicas de la población de Jaén con esta parte de su término municipal, que en este momento resulta manifiestamente mejorable. Los nuevos aprovechamientos previstos obviamente son compatibles con la conservación de los elementos patrimoniales que han motivado nuestra dedicación a Otiñar, y se entiende además que constituyen la mejor garantía para asegurar la preservación de los valores simbólicos, culturales y ecológicos reconocidos en este territorio.

Un avance de este proyecto embrionario ha sido presentado en distintos cursos y reuniones científicas, concretamente los objetivos generales del proyecto fueron el motivo de una comunicación y un panel explicativo en la I Reunión Anual de la Asociación Europea de Arqueólogos (ZAFRA y otros, 1995), y los aspectos más novedosos de la metodología y el sistema de registro se han expuesto en el II Congreso Peninsular de Arqueología (ZAFRA y otros, 1996).

Este trabajo pretende difundir ahora con más detenimiento el punto de partida y los objetivos fundamentales del proyecto Otínar. Se encuentran primero los presupuestos científicos y patrimoniales del proyecto, después nos detenemos en una cuestión aparentemente accesoria, como es el procedimiento de recogida y sistematización de la información, y terminamos con un acercamiento a posibles marcos alternativos de relación del público con el señorío de Otíñar.

En esta contribución se pueden hallar por tanto ciertas sugerencias que resulten útiles a arqueólogos/as insatisfechos/as con las perspectivas de su práctica profesional, o simplemente desalentados/as con la definición y límites de su objeto de investigación. No obstante, no ocultamos que los destinatarios pretendidos de este trabajo difícilmente se identificarán como practicantes cualificados de la Arqueología, más bien nos dirigimos a conocer las respuestas y las disposiciones de un público todavía ausente, que estaría decidido a participar en un proyecto de conocimiento e intervención en la Sierra de Jaén.

* Consejería de Cultura - Junta de Andalucía - Delegación Provincial de Jaén.

Grupo de Investigación del Patrimonio Arqueológico de Jaén. Dpto. de Territorio y Patrimonio Histórico - Universidad de Jaén 


\section{LEGITIMIDAD Y DISCIPLINA}

Se encuentran algunos discursos en torno a la Arqueología que tratan de esbozar una justificación social de la disciplina, pretendiendo renunciar a una práctica hedonista exclusivamente orientada al reconocimiento académico, y casi siempre manifestan una vocación progresista de intervenir y mejorar nuestro presente colectivo '. Tal vez este argumento legitimador sea enunciado en ocasiones para ocultar cierta perplejidad y bastante confusión ante una distancia aparentemente insalvable, que existe entre las controversias actuales y aquellos hechos y sociedades que son objeto de la investigación arqueológica. En cualquier caso, se acaba aceptando con naturalidad que el campo de actuación de la Arqueología se encuentra en el te-rreno de la ideología, acotado dentro de la reconstrucción científica del pasado, y por tanto sólo comprometido con la simple afirmación de ideas y convicciones pertenecientes a la esfera de un proyecto social ${ }^{2}$ particular.

Ni siquiera se puede exigir la difusión de estas ideas fuera del ámbito estrictamente científico como responsabilidad de la Arqueología, porque ésto vulneraría la competencia especializada de la disciplina, aunque evidentemente ésto también aportaría una mínima credibilidad al pretendido estatuto del arqueólogo o la arqueóloga como operario/a de la ideología. Sin duda, la Arqueología va a alcanzar verdaderamente esta finalidad social divulgadora sólo cuando sea capaz de proyectar en otras conciencias (y prácticas sociales) más activas y determinantes la existencia de un proyecto social alternativo y la certeza histórica de sus presupuestos.
Sin embargo, todavía la Arqueología puede reivindicar un protagonismo mayor, que desde luego no debe consistir sólo en la disputa al comercio ilegal de antigüedades de algunos elementos muebles. El ejercicio de la Arqueología requiere a menudo la ocupación temporal de un espacio en el territorio actual, donde en algunas coyunturas convergen intereses importantes que pueden parecer vitales para toda la sociedad ${ }^{3}$, y en determinadas circunstancias la protección del patrimonio arqueológico puede demandar que esa ocupación temporal se convierta en una apropiación pública definitiva. Entonces, la Arqueología deja de ser una práctica hedonista o un simple discurso ideológico para convertirse en una actividad económica y social decisiva, y desde ese momento la investigación arqueológica ha dejado de ser una compilación de referencias a ideas y convicciones para convertirse en un instrumento político de largo alcance.

La legitimación social de la Arqueología no puede sostenerse sobre un discurso limitado al seno de la comunidad cientííca, como tampoco parece razonable esperar que otras disciplinas hagan una utilización adecuada de la producción literaria o material que resulta de un estudio arqueológico. Se encuentra ampliamente extendida en Arqueología la crítica negativa de cualquier acercamiento a su objeto de estudio procedente de disciplinas consideradas intrusas, como son entre otras la arquitectura, la museología, el periodismo o la pedagogía, porque vienen a mostrar la incapacidad de la propia Arqueología para ocupar una posición en la sociedad actual fuera de su dimensión estrictamente académica. La ferocidad de esta crítica se puede relacionar directamente con las limi-

\footnotetext{
I No obstante, los discursos legitimadores más comunes insisten casi exclusivamente en la naturaleza liberadora de la reconstrucción científica, entendiendo que el simple conocimiento histórico como una especial verdad vendrá a reforzar el sentimiento crítico de sus hipotéticos receptores. En realidad, la única hecatombe segura derivada del proyecto arqueológico se debe esperar en el mismo ámbito académico que ha amparado la investigación.

Se encuentra más veces el argumento del conocimiento científico como factor determinante para la defensa y protección del patrimonio arqueológico (por ejemplo, ver RUIZ y otros, 1987).

2 Se hace referencia a la existencia de una estrecha conexión conceptual y programática entre teoría histórica, economía política y proyecto social (FONTANA, 1982), de manera que el análisis del pasado, la afirmación de determinadas posiciones políticas y la identificación con un modelo social futuro constituyen tres vertientes de un único bloque ideológico.

3 Los factores de riesgo de destrucción del patrimonio arqueológico más importantes se encuentran no tanto en actuaciones puntuales de expoliación, como en los grandes proyectos de modernización del tejido territorial (infraestructura viaria, urbanización, regulación hidráulica,...), que normalmente cuentan con una amplia aceptación social.
} 
taciones del discurso arqueológico para tender puentes interdisciplinares, y casi siempre demuestra una voluntad de aislamiento y autocomplaciente introspección destinada a mantener el control académico exclusivo de una parcela de conocimiento.

El proyecto Otíñar viene a sostener que la bondad de una investigación arqueológica debe seguir siendo medida por la envergadura de su aportación al conocimiento cientííco, pero que ahora también necesita ser avalada por su implicación en acciones y proyectos concretos. Probablemente, estos proyectos derivados del hecho de conocer estén destinados a veces a disentir de los usos y las relaciones de apropiación consolidadas en nuestra actualidad, compitiendo de esta manera con otras iniciativas constituidas de intervención económica o social en el territorio.

En este sentido, la única legitimación posible de la Arqueología se encuentra en su capacidad para conocer los episodios formativos del territorio $y$, de esta manera, aportar argumentos dirigidos a mediar, discutir y asegurar la racionalidad de su aprovechamiento y planificación. La configuración incluso de un espacio para la memoria, que sin duda constituye la más aceptable aportación de una investigación arqueológica, sólo resulta una operación sencilla si cuidadosamente se bordean determinados espacios conflictivos ${ }^{4}$. El empeño mostrado por casi todos los proyectos arqueológicos para eludir estos espacios abiertos de enfrentamiento y tensión, que son aquellos donde verdaderamente aparecen riesgos inmediatos para el mantenimiento de la integridad material de una parte significativa del patrimonio arqueológico, sólo se puede explicar por la acomodación negativa de la disciplina y su práctica académica a los requerimientos de estrategias de ocupación del territorio que son destructivas de los valores patrimoniales y ambientales descubiertos en el mismo.
En definitiva, pretendemos afirmar que toda investigación arqueológica se encuentra encaminada a comprender el contexto social y territorial de su ámbito de actuación, y se dispone a intervenir activamente en el mismo, o por el contrario aparece como un ejercicio de conocimiento estéril que no puede amparar ninguna dedicación de medios y esfuerzos.

Esta perspectiva de intervención territorial vinculada al proyecto arqueológico puede adquirir aún una dimensión mayor, si se advierte que la legislación vigente confía en la metodología desarrollada en cada momento por la Arqueología para definir aquellos bienes que tienen la consideración de patrimonio arqueológico. La Ley 16/1985, de 25 de junio, del Patrimonio Histórico Español, reconoce la capacidad de la Arqueología para definir su propio objeto de investigación a través de una metodología determinada, otorga a ese objeto de conocimiento la calidad de patrimonio arqueológico, y por tanto despliega sobre el mismo las medidas de protección genérica dispuestas en la normativa, que condicionan cualquier intervención en los bienes afectados a la conservación de su valor e interés histórico.

\section{LÍMITES DE UNA DEFINICIÓN PATRIMONIAL}

La legislación vigente ha renunciado a hacer una enumeración exhaustiva y concisa de los bienes integrantes del patrimonio arqueológi$\mathrm{CO}^{5}$. Esta indefinición del concepto de patrimonio arqueológico, situada en el origen del ordenamiento jurídico, puede tener consecuencias imprevisibles en el momento de su interpretación por la Administración pública, y tal vez no se deba esperar que siempre sea entendida para garantizar la protección de todos aquellos bienes que pueden ser estudiados desde la Arqueología. Sin embargo, esta misma indefinición también puede ser utilizada en sen-

\footnotetext{
${ }^{4}$ El contexto adverso para la conservación del patrimonio arqueológico se encuentra en su aislamiento social frente a otros intereses más compartidos o, simplemente, más poderosos y dominantes (ver nota 3).

${ }^{5}$ Ley 16/1985, de 25 de junio, del Patrimonio Histórico Español (B.O.E. núm. 155, de 29 de junio de 1985): art. 40. I. Conforme a lo dispuesto en... forman parte del Patrimonio Histórico Español los bienes muebles o inmuebles de carácter histórico, susceptibles de ser estudiados con metodología arqueológica...
} 
tido contrario para permitir la permanente actualización del concepto de patrimonio arqueológico y, en principio, una expansión del mismo en apariencia ilimitada, dependiendo únicamente de la existencia de un acuerdo general en la disciplina arqueológica para definir una metodología común.

Así, se defiende que la Arqueología no sólo ocupa un sitio en el territorio actual, también puede revisar los límites, la fisonomía y los componentes del lugar que es objeto de estudio, y de esta manera está extendiendo o aminorando las limitaciones de usos y aprovechamientos que la legislación vigente reconoce como inherentes a los bienes arqueológicos. La ambigua definición de los bienes afectados por la categoría jurídica de patrimonio arqueológico, y las dudas cada vez más extendidas entre las administraciones de los bienes culturales o judicial sobre la viabilidad de una interpretación abierta del concepto, exige situar de manera consciente la práctica de la Arqueología en el mismo seno de la controversia social o, en caso contrario, cualquier discurso legitimador se mantedrá objetivamente privado de todo significado coherente, apareciendo como irrelevante para la conservación del patrimonio arqueológico.

El carácter progresista de la legislación vigente ha trasladado al plano jurídico una discusión acerca de la naturaleza y los límites de los bienes integrantes del patrimonio histórico, que hasta este momento sólo había sido formulada en el ámbito de la ciencia y la cultura. La interpretación de la norma va a estar condicionada sin duda por el desarrollo metodológico de la Arqueología y, en general, por la aceptación mayoritaria de determinados criterios de valor relacionados con los bienes culturales. No obstante, estas circunstancias no dejarán de ser simples opiniones técnicas y cualificadas si no se demuestra que existe una conexión viva entre las mismas y los intereses de la mayoría de la población. De esta manera, se puede afirmar que la justificación de la Arqueología va a continuar siendo una elaboración discursiva hasta tanto la disciplina pueda demostrar una utilidad social inmediata, que por otra parte resulta imprescindible para abor- dar con ciertas garantías de éxito la misma conservación del patrimonio arqueológico.

Siguiendo a Walter Benjamin (en HABERMAS, 1989: 26), desconfiamos del tesoro de bienes culturales que cada actualidad se apropia, como también del uso prefigurado para los mismos. El proyecto Otíñar tiene razones para creer que no se trata de una simple sospecha la lejanía de su objeto de investigación del tesoro recuperado y actualizado. La definición patrimonial más común descansa todavía en la reivindicación monumental de elementos aislados en el territorio y pretendidamente únicos. Se reconoce el valor histórico de los mismos en un conjunto de rasgos que definitivamente el paisaje agrario no tiene $y$, en particular, el paisaje configurado por nuestro pasado (agrario) más inmediato. La exigencia de negar toda historia y todo patrimonio cultural que no sirva a la justificación de nuestro presente, que siempre contiene también un proyecto de futuro ya decidido y cerrado, constituye un argumento fuerte para señalar a esa historia agraria reciente como intrísecamente vergonzante, vetar su consideración como patrimonio histórico y, en última instancia, obstaculizar la investigación de sus restos materiales.

Se puede afirmar que el paisaje agrario tradicional constituye una identidad postergada por la imposición de un modelo de desarrollo unidireccional, que despliega profundas transformaciones del medio rural y acaba exigiendo el desmantelamiento casi completo de aquellas evidencias culturales que han sido modeladas por la sucesión de distintas formas de ocupación y aprovechamiento a lo largo del tiempo. El objetivo central del proyecto Otíñar consiste justamente en promover en la comunidad la asunción de una memoria común acerca de su pasado agrario, y actualizar su propia identidad cultural a través de distintas estrategias, que persiguen primero la aceptación del territorio agrario como un bien patrimonial, segundo la conservación y comprensión de sus rasgos más sobresalientes, y tercero el estudio y la propuesta de usos compatibles con la preservación de su integridad material.

Efectivamente, los objetivos planteados en el proyecto Otiñar hacen que no sea un pro- 
yecto convencional de conocimiento e investigación, mas bien se puede entender como un proyecto de intervención planificada. Este proyecto trata de dar respuesta a la escasa incidencia en la comunidad que las investigaciones arqueológicas han tenido hasta ahora, y se fundamenta en una definición amplia y revisada del objeto particular de la Arqueología, que se identifica con la totalidad material socialmente apropiada (FUNARI, 1989) y, en esta medida, se sostiene que toda entidad material susceptible de interpretación histórica puede ser considerada como parte integrante del patrimonio arqueológico.

\section{EL OBJETO DEL PROYECTO}

El objeto del proyecto Otínar se ha definido en términos provocadoramente marginales, tanto en su proyección espacial como en las coordenadas temporales del mismo. Se han seleccionado un lugar, delimitado siguiendo los confines de una propiedad privada, y un tiempo, los siglos XIX y XX, que pueden parecer ajenos a una investigación arqueológica convencional.

El señorío de Otínar, hoy un latifundio despoblado, se constituye hacia 1834 en un momento de ascensión política de la burguesía andaluza, ocupando una superficie de 1700 ha. en torno al río Quiebrajano en las estribaciones de la Sierra de Jaén, que hasta entonces formaba parte de los bienes de propios del Ayuntamiento de Jaén. Se trata de abordar en este medio la reconstrucción de la historia de una comunidad agraria y su territorio a través de las grandes transformaciones sociales y económicas de los siglos $X I X$ y $X X$.

El tiempo y el lugar que merecen la atención del proyecto introducen la posibilidad de evaluar de manera crítica los resultados del análisis arqueológico, procediendo a su enfrentamiento sistemático con la información suministrada por otras fuentes documentales realmente exhaustivas, que van desde la memoria viva a los archivos eclesiásticos. Esta perspectiva permite augurar que la investigación de Otínar va a proporcionar también un contraste riguroso del alcance y limitaciones de la metodología arqueológica aplicada al territorio.
La continuidad observada en las formas y evidencias superficiales generadas por las actividades agrarias tradicionales asegura la unidad e integridad del señorío de Otíñar como una vasta zona arqueológica, que asimismo comprende vestigios dispersos de etapas anteriores del paisaje agrario y un conjunto de sitios, como el castillo, el dolmen, las pinturas rupestres o el despoblado medieval, que apenas tendrían sentido fuera de este marco territorial. El paisaje agrario aparece sin duda como el escenario más adecuado de estos elementos singulares, y además puede prestar un apoyo adicional para facilitar la comprensión por el público del significado de los mismos, haciendo patente la permanencia histórica de determinado aspectos de su contexto espacial original.

El proyecto Otiñar pretende apoyarse en ese pasado reciente para regenerar un territorio manifiestamente mejorable, porque entendemos el patrimonio arqueológico como una realidad concreta, estructurada, cambiante e inacabada, que puede ser investigada y planificada hasta constituirse en un factor decisivo de desarrollo equilibrado y cohesión social. Una vez aceptado este presupuesto, el proyecto se enfrenta a una investigación histórica total del territorio, que requiere en primer término una comprensión acertada de su compleja configuración material y simbólica y, en segundo lugar, la planificación de un modo de acercamiento y registro adecuado a esa complejidad advertida. Las necesidades de captura, ordenación y manipulación de un conglomerado de información extenso y heterogéneo, como también la diversidad de intereses e hipótesis iniciales, nos ha llevado a construir un programa de documentación ad hoc, que ha exigido la revisión crítica de los modelos de registro usuales.

\section{EL PROGRAMA DE DOCUMENTACIÓN}

Registrar en Arqueología equivale a seleccionar y ordenar datos, que acaban conformando un cúmulo de información concreto entre otros posibles. Se procede a salvaguardar un aspecto fragmentario de la totalidad 
material socialmente apropiada, que intuitivamente deseamos esté constituido de manera significativa. No obstante, el conocimiento parcial y desestructurado, aportado por la mayoría de los proyectos arqueológicos convencionales, parece demostrar que casi nunca se encuentra un significado realmente proporcionado a la envergadura del esfuerzo invertido en recopilar información.

\section{Registro y conocimiento}

Los intentos de unificar las bases interpretativas o cuerpos de datos de los procesos de investigación se plasman en modelos de registro, que son herramientas metodológicas formalizadas de tal modo que, por un lado, sistematizan toda la información recogible (=reconocible) y, por otro, organizan el trabajo del/la arqueólogo/a dentro de la jerarquía establecida entre los miembros del grupo de investigación. El modelo consiste generalmente en una serie de fichas referenciadas, donde se ubican en determinado orden todas las evidencias y muestras apreciadas en la intervención arqueológica, y suele ser característica la rigidez del planteamiento y organización del sistema de información. Puede parecer que estos modelos están diseñados para satisfacer determinadas necesidades formales de carácter científico y académico, nunca para favorecer un proceso real de conocimiento.

El punto de partida del proyecto Otíñar exige que los resultados científicos se integren en el marco de los documentos técnicos, pero en nuestro caso no como apéndices o bases de datos sistemáticas sino como parte activa de la misma estructura hipotética del proceso de investigación. Se puede desprender fácilmente de este requerimiento que los sistemas de registro convencionales no resultan aprovechables en su totalidad para nuestros fines. También encontramos discrepancias importantes en los mismos presupuestos del hecho de registrar, que de manera sucinta se exponen a continuación.

Se considera, por ejemplo, el registro como la asociación de materiales y sedimentos en el yacimiento (VARGAS, 1990:20; BUTZER, 1989:221), equiparando registro y yacimiento, de donde se puede concluir que el registro es el resultado de la observación y a la vez el objeto observado. Se admite también que la observación puede ser neutral, llegando a afirmarse que el registro no se elabora, simplemente se recupera, y por tanto la calidad del mismo depende más de la pericia mecánica del arqueólogo que de la pertinencia de las preguntas iniciales. En esta línea, una planteamiento extremo del enfoque llega a considerar que el registro no pretende reproducir la realidad, sino sustituirla. Parece evidente que toda observación es selectiva y deliberada, y pretendiendo imponer criterios de utilidad, no podemos compartir estas concepciones del registro en Arqueología.

Asimismo, se debe subrayar que los modelos de registro disponibles suelen centrarse en el yacimiento, sin duda un concepto de zona arqueológica restrictivo que margina a los territorios no urbanizados y, por tanto, obtiene una imagen interrumpida, sólo habitada por ruinas urbanas que son las que obviamente reconocemos desde nuestro pensamiento también urbano. De esta manera, el espacio arqueológico es entendido como un espacio construido, una reducción de esta noción que nos sugiere una imagen cósmica donde las estrellas penden de la nada. Por último, los sistemas de documentación se suelen concentrar en el proceso de excavación, que en nuestro caso no es la principal fuente de información.

Considerando que el proyecto Otiñar se dispone a utilizar en origen un nivel de información muy superior al que por regla general se obtiene al final de la mayor parte de las investigaciones arqueológicas, y considerando también la crítica apuntada de los sistemas de información disponibles, se comprenderá que no tuvieramos otro remedio que diseñar un modelo de registro ad hoc, que nace con la pretensión de ser abierto y, en cierto modo, orgánico y vivo. Si bien su columna vertebral sigue siendo una base de datos georeferenciada, su forma de capturar la información y de gestionarla debido a su versatilidad admite muchas y variadas lecturas. 


\section{Estructura del sistema de información}

La estructura del sistema de información constituye la columna vertebral del proyecto, y esperamos dotarla de flexibilidad suficiente para soportar orientaciones diversas de la investigación y facilitar la constante relectura de los datos duros recopilados en el transcurso del tiempo. Si las entradas y salidas del sistema pudieran ser previstas en el mismo origen del programa de investigación durante la fase de proyecto, sería razonable incluso prescindir de la misma ejecución del programa, o en todo caso orientarlo hacia la recopilación selectiva de datos puntuales. Un esquema de la estructura del sistema de información ha sido reproducido como si fuera un documento generado por el propio sistema (ver fig. I).

\section{Áreas de investigación}

La información básica, la que necesitamos para cubrir los objetivos se ha enmarcado en áreas de investigación (ver fig. I), que no son los clásicos compartimentos estancos adecuadas a las distintas disciplinas de apoyo a la Arqueología, sino que pretenden ser integradoras de saberes de diversos campos. La investigación se desarrolla en tres grandes áreas, que atienden a la descripción y el análisis del territorio actual, la restitución hipotética de algunos episodios precedentes de este territorio y la definición de las correspondientes estrategias sociales que los conforman.

Se trata de indagar en la configuración cambiante de un espacio a través del tiempo para establecer aquellos rasgos y procesos que fueron determinados por relaciones sociales significativas. Cada una de estas áreas pretende sostener un enunciado teórico sobre los procesos formativos de un universo físico particular, advertido como sucesivas apariencias en un espacio a través del tiempo. Estas áreas de investigación están delimitando tres vertientes del objeto de investigación y recabando información de naturaleza diversa.

Nuestra experiencia y las condiciones en las que pretendemos abordar esta investigación nos aconsejan una extraordinaria cautela a la hora de desechar los frutos de cualquier esfuerzo de observación y registro, como también el aprovechamiento eficaz de cualquier contacto con el objeto de nuestro trabajo.

La primera área de investigación es Topografia y dinámica ambiental. La configuración actual del territorio está sometida a procesos de cambio de naturaleza física. El territorio constituye una realidad dinámica expuesta a fórmulas y pautas de modificación similares ahora y en el pasado. Considerando que el tiempo de nuestra documentación casi siempre nos obliga a referirnos a episodios forzosamente diferentes, se podrían fijar los cambios ocurridos en un mismo rasgo $y$, de esta manera, se estaría contribuyendo a desvelar el ocultamiento de una realidad originaria recorriendo en sentido inverso los procesos activos de configuración del territorio, detectando de paso determinados condicionamientos inherentes a ese marco físico.

La segunda área de investigación se denomina Configuración histórica del territorio. Los territorios se encuentran organizados de manera significativa. Esta organización puede ser reducida a modelos de ordenación espacial, que definan los distintos componentes e interpreten sus relaciones básicas. Todo modelo espacial reconoce un límite físico, histórico, tecnológico o social y se encuentra articulado en unidades homogéneas, definidas por límites secundarios que presentan la misma naturaleza de los anteriores. La incapacidad de cualquier modelo espacial para dar cuenta de la apariencia cambiante de un paisaje a través del tiempo está indicando el equilibrio inestable del mismo, que obedece a procesos determinados de naturaleza física y social.

Por último, la tercera área de investigación se reconduce bajo el epígrafe Tiempo social y modos de vida. Una vez determinada la influencia de los procesos físicos en la transformación del paisaje, los demás cambios observados obedecen a estrategias sociales constituidas, que son susceptibles de intuirse en los límites de un modelo espacial anterior y de moldear un espacio óptimo y utópico. Las transformaciones en el territorio permiten inferir los cam- 
bios ocurridos en el seno de la organización social, que pueden señalar conflictos en los episodios precedentes y caracterizar proyectos sociales definidos.

\section{Líneas de documentación}

Las tres áreas señaladas agrupan distintos conjuntos de actuaciones, caracterizados por el enunciado de una hipótesis previa y dispuestos para minimizar el esfuerzo de la investigación, a los que denominamos líneas de documentación. De este modo la Topografia y dinámica ambiental, primera área de investigación, contendría un número indeterminado de líneas de documentación, entre las que pueden figurar las siguientes: Dinámica estacional, Momentos o umbrales de tensión, génesis de las comunidades vegetales, etc. (ver fig. I).

\section{Actuaciones documentales}

El contraste de esas hipótesis exige determinadas Actuaciones que fijan unas condiciones homogéneas de observación y registro. Naturalmente estas Actuaciones generan documentos (únicos o agrupados en archivos), que son conjuntos de información estandarizada relativa a una unidad mínima de observación y registro (ver fig. 3 a 9).

\section{Archivos y documentos}

Estos documentos son la evidencia física del estudio, todo lo demás es una estructura lógica para sostenerlo y hacerlo comprensible. Los documentos son lo que elaboramos en la fase de recogida de datos y articulan el discurso.

El documento (la ficha) tiene dos partes bien diferenciadas. La primera (fig. 4, 6 y 8 ) está pensada para identificar y describir el objeto estudiado. Se pueden señalar como objetos del sistema de información, a modo de ejemplo, uno de los dólmenes, un tramo del río, un árbol, una parcela, un camino, una encuesta o un fragmento bibliográfico, depende del área de investigación y de la línea de documentación a la que se adscriba, que figura mediante códigos en el encabezamiento, y de la escala y la resolución de la actuación (ver fig. 2).
Se incluye el título y código de la actuación y del documento. Los códigos son básicos ya que representan la vía de conexión de todo el sistema.

La segunda parte de la ficha (fig. 5, 7 y 9) es la que funciona como una base de datos $y$ permite establecer toda clase de relaciones horizontales y verticales. El documento en cierto modo es bastante convencional, nos ocupamos de establecer en el mismo sus características y las precisiones de espacio y tiempo mínimas para geo-referenciarlo y crono-referenciarlo (fig. 3). Existe un espacio considerable dedicado a establecer las conexiones con otros documentos relacionados, en este caso sólo bibliográficos, pero que pueden ser otros generados en distintas revisiones o elaborados a otra escala o distinta resolución.

En definitiva, el programa de documentación persigue romper con una inocencia descorazonadora, que concibe el registro como una especial máquina de fotografiar coyunturas ( $y$ al arqueólogo como un cazador-recolector de instantes), olvidando que sin una teoría un conjunto de representaciones sustituirá al objeto de conocimiento, y su arbitrariedad subjetiva será la emanada desde instancias jerárquicamente superiores en el proceso de investigación. En este caso, la zona arqueológica será una colección de datos ordenados, una serie reducida a números con pretensiones de clasificación total, y el arqueólogo está dispuesto a admitir que ha agotado con ella el universo observado y puede pasar a incluirla en el compartimento que le corresponda dentro de la discusión académica.

Se podría resumir que para alejarnos de ese destino, en nuestra investigación ponemos el registro al servicio del proyecto de conocimiento, y cuidadosamente evitamos la situación contraria. Se rompe con ello la rigidez mecánica de la extracción de datos convencional (unida a la idea de yacimiento) al aceptar que el objeto estudiado es el territorio actual, vivo y transformable en el que existe una disfunción entre lo que es y lo que debe ser, y en el que podemos actuar como agentes y no como meros espectadores. Sólo nos queda 
desear que toda la información que obtengamos y la planificación que de ella nazca puedan ser aplicadas a ese territorio en su beneficio y, por tanto, en beneficio de la comunidad asentada en el mismo.

\section{MODELOS BÁSICOS DE APROVECHAMIENTO}

Naturalmente establecer unos modos de aprovechamiento social del territorio abarcado por el proyecto Otínar sería lo mas adecuado para finalizar este trabajo. No obstante, en el momento actual no estamos en condiciones de definir estos modos con precisión, aunque sí se pueden establecer unos marcos operativos globales.

Desde el principio hemos visto como parte del diseño de investigación la necesidad de proponer modos de aprovechamiento social del producto obtenido por el estudio e incluso del proceso de estudio. La forma de abordar las decisiones de delimitación del territorio y de presentar los datos contienen en si mismas un programa de información pública, que en este caso se muestra como definitivo para hacer posible uno de los presupuestos básicos del proyecto, el de implicar a la población afectada por las decisiones que se van tomar.

En realidad, proponemos un ejercicio de planificación para este territorio que desarrolle una actividad pública de ordenación (planeamiento), estudiando las necesidades y aspiraciones del grupo social hacia el que nos dirigimos (en este caso, las/los ciudadanas/nos de Jaén), con el objetivo de organizar acciones que, incidiendo sobre las condiciones existentes, modifiquen la situación actual hacia nuevos modelos de uso e incluso de propiedad del territorio.

En este marco general de aprovechamientos podríamos hacer una primera distinción según la propiedad: de un lado los aprovechamientos públicos generales y de otro los aprovechamientos privados compatibles. En la primera categoría hemos de incluir las actividades cotidianas de ocio y esparcimiento, es decir, el uso del lugar como parque, ya ensayado en la zona próxima de la Cañada de las Hazadillas y Embalse del Quiebrajano que ya cuentan con un tratamiento especifico como Parque Periurbano en el Plan General de Ordenación Urbana de Jaén. Se trataría de una ampliación y cualificación del espacio protegido como parque potenciando usos que en la actualidad no son muy conocidos.

Otras formas de aprovechamientos de carácter público a crear y potenciar son las docentes, las culturales y de difusión institucional ya que este tipo de actividades poseen un efecto multiplicador en el conocimiento y difusión del sitio en si y de las posibilidades asociadas a él como las que antes hemos mencionado de ocio y esparcimiento. Un diseño de material didáctico específico elaborado en colaboración con los Gabinetes Pedagógicos de Bellas Artes y la práctica de éste en unas Jornadas como las del Patrimonio Europeo es un proyecto de difusión muy adecuado para los objetivos previstos, ya que las iniciativas que hasta ahora ha lanzado el Movimiento Vecinal de Jaén en la zona con el objetivo de practicar el senderismo han tenido una respuesta muy favorable, que creemos posible mejorar introduciendo nuevos intereses: los aportados por la investigación arqueológica e incluso el relato de ésta.

En este mismo sentido, las actividades turísticas es necesario fomentarlas sin perder de vista la idea básica del proyecto, es decir, la posibilidad de reconstruir la historia y formación del territorio que mostramos, aunque considerando las posibilidades de incorporación de la financiación privada y por tanto dando posibilidades de introducción de nuevas ideas que generen una dinámica favorable en la zona tal vez mas basadas en el aprovechamiento visual paisajístico natural de la zona. Otra alternativa para el uso y financiación privados, aunque podrían inicialmente ser apoyada mediante subvenciones, es la práctica de agricultura tradicional.

En definitiva, el proyecto Otiñar propone utilizar todos los medios conocidos e indagar en algunos menos conocidos para recuperar un espacio extenso de la Sierra de Jaén. Nos interesa idear fórmulas de musealización novedosas de un territorio cuya historia de formación 
vamos a recuperar mediante la investigación arqueológica, nos proponemos trabajar desde el principio con la participación de los destinatarios finales para ver como es posible mejorar el producto final mediante esta estrategia participativa.

\section{BIBLIOGRAFÍA}

BUTZER, K.W. (1989): Arqueología, una ecología del hombre. Método y teoría para un enfoque contextual. Bellaterra, Barcelona.

FONTANA, J. (1982): Historia. Análisis del pasado y proyecto social. Crítica, Barcelona.

FUNARI, P.P.A. (1989): Arqueologia. Atica, Sao Paulo.

\section{RESUMEN}

Este artículo presenta la metodología y los fundamentos patrimoniales del proyecto El Señorío de Otínar ( 1834 1975), que persigue la reconstrucción de los episodios formativos del paisaje de una comunidad agraria desde su establecimiento en la Sierra de Jaén a mediados del siglo pasado hasta la despoblación de la aldea central en 1975, y proponer un modelo de recuperación de este lugar para su uso público. Los elementos que componen este paisaje agrario han permanecido hasta ahora al margen de cualquier valoración patrimonial, y su interpretación debe permitir la incorporación de los mismos al patrimonio histórico andaluz para asegurar su conservación y uso público.

Nuestro trabajo pretende contribuir a la autovaloración social de la comunidad a través de dos mecanismos diferentes, como son la participación de la propia comunidad en la reconstrucción oral de su pasado y la preservación de un conjunto patrimonial representativo del modo de vida tradicional. El proyecto se presenta también como un ejercicio crítico acerca del alcance de la metodología arqueológica, habiendo seleccionado con este propósito un objeto que admite otras alternativas de reconstrucción, basadas tanto en la tradición oral como en la documentación administrativa.
HABERMAS, J. (1989): El discurso filosófico de la modernidad. Taurus, Madrid.

KOSIK, K. (1967): Dialéctica de lo concreto. Grijalbo, México.

RUIZ, A.; MOLINOS, M. y HORNOS, F. (1987): Arqueología en Jaén. Reflexiones desde un proyecto arqueológico no inocente. Exma. Diputación Provincial de Jaén, Jaén.

VARGAS, I. (1990): Arqueología, ciencia y sociedad. Abrebrecha, Caracas.

ZAFRA, N; CASTRO, M. y HORNOS, F. (1996): El registro arqueológico en los estudios integrados: su función en el proyecto Otiñar. Actas del II Congreso Penínsular de Arqueología, Zamora. e.p.

ZAFRA, N; HORNOS, F. y CASTRO, M. (1995): El señorío de Otínar. Una reivindicación patrimonial del pasado reciente. I Reunión Anual de la Asociación Europea de Arqueólogos, Santiago de Compostela. Inédito.

\section{ABSTRACT}

This paper presents the methodology and the hereditary reasons of the proyect The Manor of Otiñar (1834-1975), that pursues the reconstruction of the formative episodes of an agrarian community's landscape from its establishment on the Sierra of Jaén in the middle of the last century to the depopulation of the head village in 1975, and that propounds a recuperation model of the place for its public use. The elements composing this agrarian landscape have remained up to now outside to any hereditary valoration, and their interpretation must be brought up to date in the framework of the andalusian historical heritage in order to assure their conservation and public use.

Our work seeks to contribute to the social selfvaluation of the community through two different mechanisms, as are investment of that comunity in the oral reconstruction of its past and the preservation of a hereditary unit which represents the traditional way of life. The project proposed too as a critical exercise about the reach of the archaeological methodology, having selected with this purpose an object which admits other alternatives of reconstruction, based on oral tradition as well as on the administrative documentation. 
PROYECTO OTIÑAR

\begin{tabular}{|ll|l|}
\hline ACTUACIÓN: & Metodología & Cód. 112 \\
\hline DOCUMENTO: & Tabla de objetivos históricos & Cód. 11201 \\
\hline
\end{tabular}

METODOLOGÍA

\begin{tabular}{|c|c|c|}
\hline Areas de Investigación & Líneas de documentación & Actuaciones \\
\hline $\begin{array}{l}\text { TOPOGRAFÍA Y DINÁMICA } \\
\text { AMBIENTAL }\end{array}$ & $\begin{array}{l}\text { Dinámica estacional } \\
\text { Umbrales críticos } \\
\text { Catástrofes naturales } \\
\text { Condicionamientos del relieve } \\
\text { Génesis de las comunidades } \\
\text { vegetales actuales } \\
\text { Procesos mecánicos de modelado } \\
\text { Caracterización de superficies y } \\
\text { tendencias evolutivas } \\
\text { Etc. }\end{array}$ & $\begin{array}{l}\text { Localización de recursos hídricos } \\
\text { superficiales } \\
\text { Localización de recursos hídricos } \\
\text { subterráneos } \\
\text { Recopilación de valores medios } \\
\text { de temperaturas y precipitaciones } \\
\text { Localización de procesos erosivos } \\
\text { Localización de áreas degradadas } \\
\text { Reconocimiento de efectos de las } \\
\text { riadas } \\
\text { Etc. }\end{array}$ \\
\hline $\begin{array}{l}\text { CONFIGURACIÓN HISTÓRICA } \\
\text { DEL PAISAJE }\end{array}$ & $\begin{array}{l}\text { Espacios construidos } \\
\text { Distribución de usos y } \\
\text { aprovechamientos } \\
\text { Caracterización de espacios agrarios } \\
\text { Hitos y sistemas de referencia } \\
\text { Redes de abastecimientos y tránsito } \\
\text { Modelos de ocupación } \\
\text { Etc. }\end{array}$ & $\begin{array}{l}\text { Localización de vegetación de: } \\
\text { - rivera } \\
\text { - borde de camino } \\
\text { - tierrade labor } \\
\text { - sotobosaue } \\
\text { - monte alto } \\
\text { - pradera } \\
\text { - badlios } \\
\text { Reconocimiento de límites } \\
\text { de parcelas } \\
\text { Determinación de usos del suelo } \\
\text { Delimitación de evidencias } \\
\text { constructivas } \\
\text { Fechación de terrazas fluviales. } \\
\text { Etc. }\end{array}$ \\
\hline $\begin{array}{l}\text { TIEMPO SOCIAL Y MODOS DE } \\
\text { VIDA }\end{array}$ & $\begin{array}{l}\text { Recolección y otros usos marginales } \\
\text { E trabajo doméstico } \\
\text { Lugares comunes: uso y } \\
\text { representación social } \\
\text { Integración temporal y } \\
\text { relaciones externas } \\
\text { Etc. }\end{array}$ & $\begin{array}{l}\text { Determinación de la procedencia } \\
\text { de los colonos } \\
\text { Determinación de la evolución } \\
\text { demogrática } \\
\text { Distribución de la población } \\
\text { Organización estacional del trabajo } \\
\text { Evidencias de especialización } \\
\text { Etc. }\end{array}$ \\
\hline
\end{tabular}

Fig. I. Documento relativo a la estructura del sistema de información 


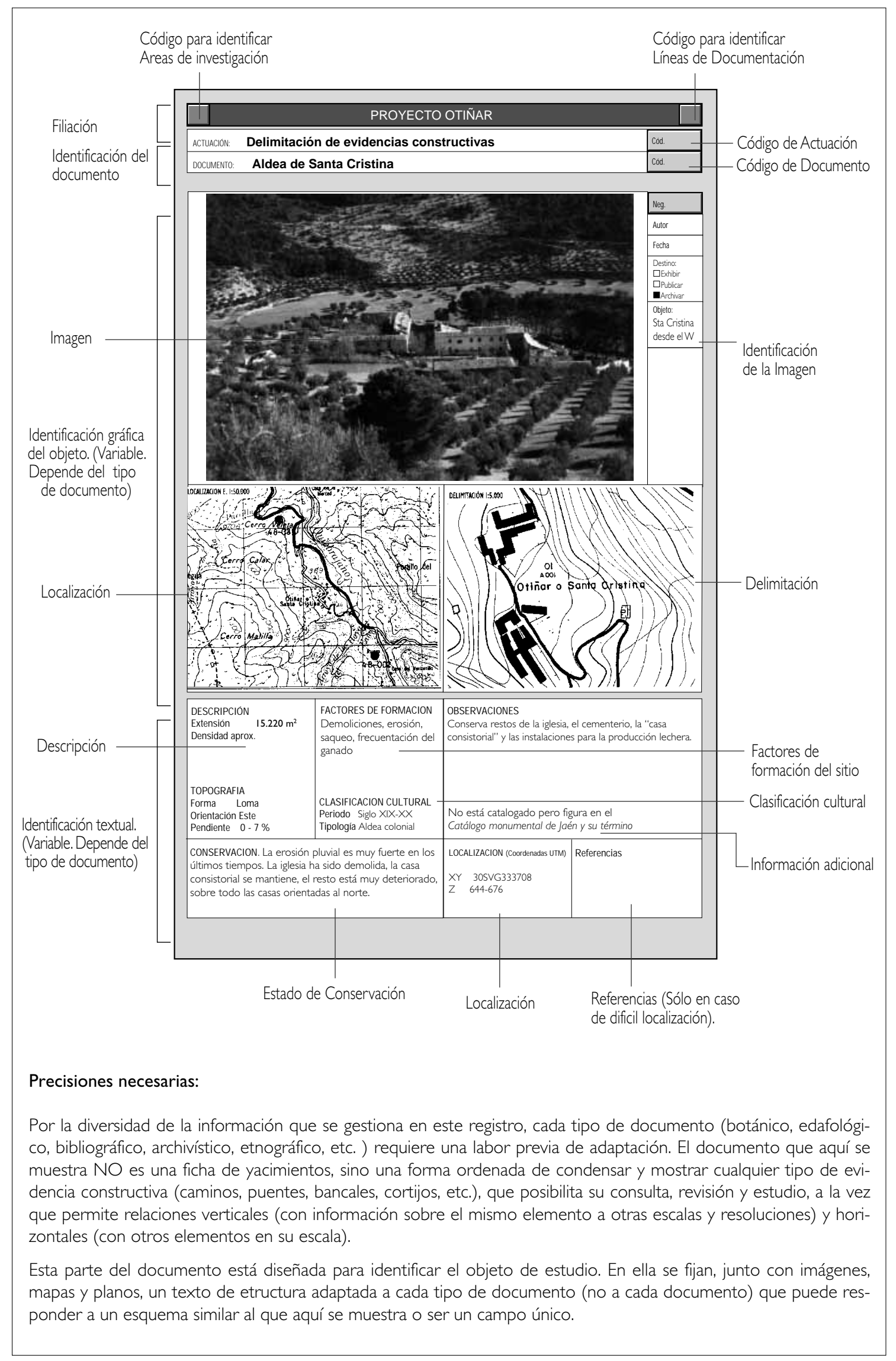

Fig. 2. Descripción de los apartados informativos de un documento-tipo. 


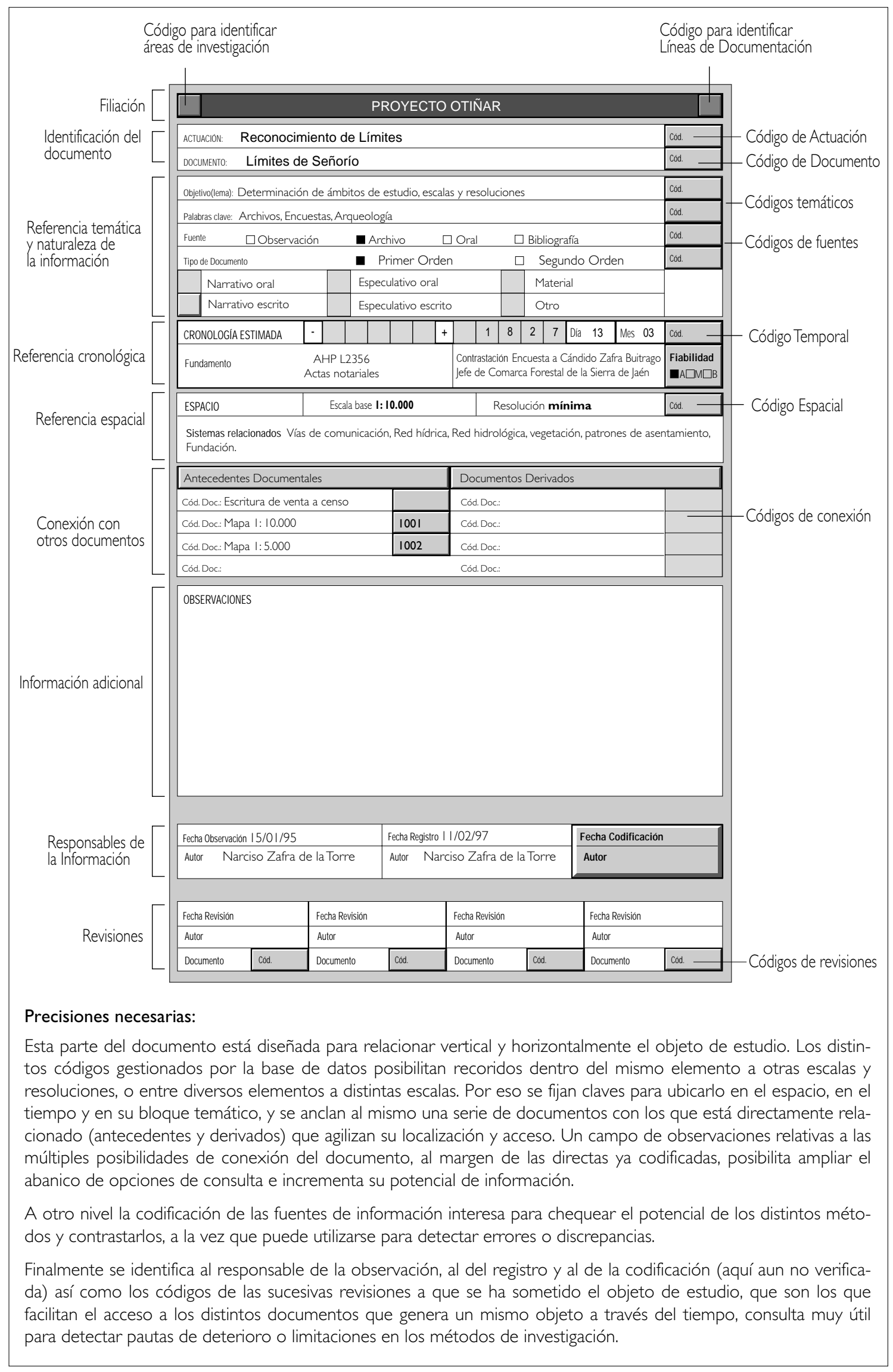

Fig. 3. Descripción de los apartados relacionales de un documento-tipo. 


\begin{tabular}{|ll|l|}
\hline ACTUACIÓN: & Reconocimiento de Límites & Cód. \\
\hline DOCUMENTO: & Límites de Señorío & Cód. \\
\hline
\end{tabular}

Imagen

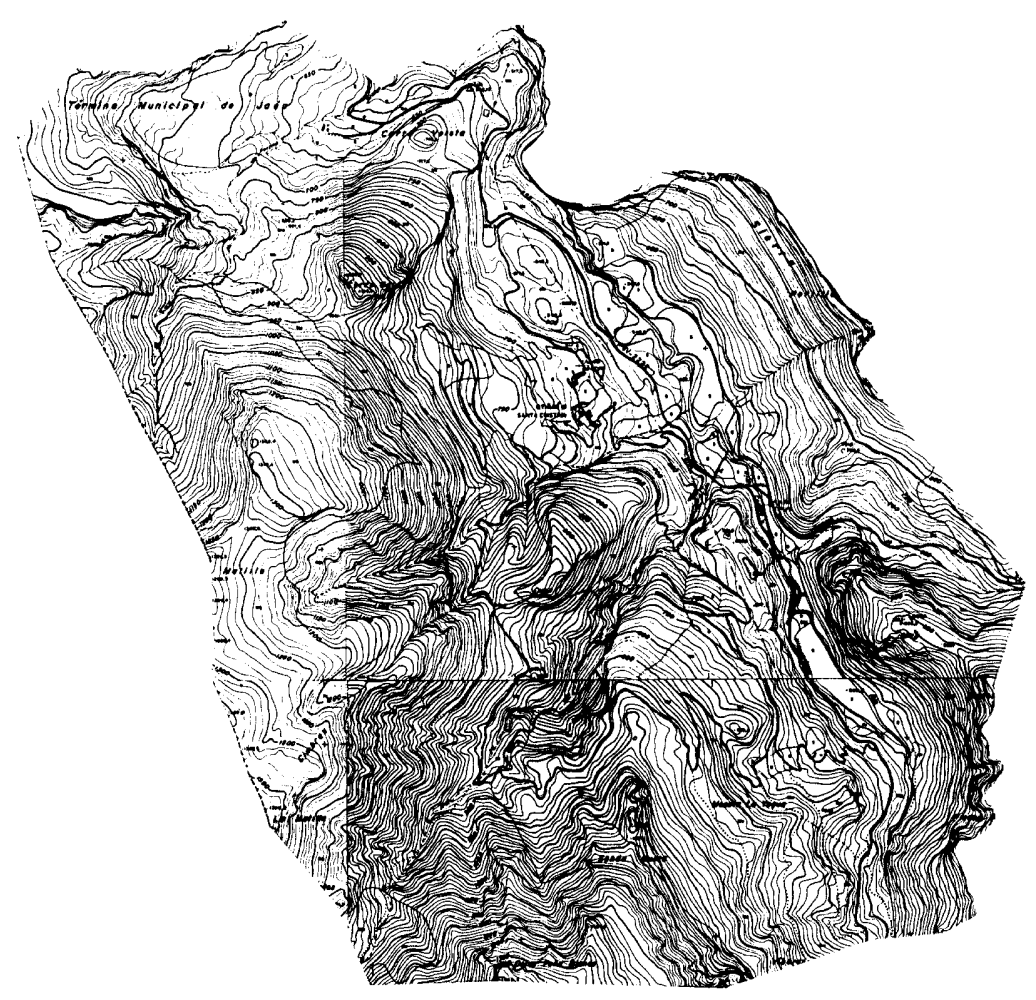

Extraido de la ESCRITURA DE CENSO DE LOS CUARTOS DE OTINAR Y LA PARRILLA. EL SR. INTENDENTE DE RENTAS A FAVOR DE D. JACINTO CAÑADA ROJO fechado en Jaén el I 3 de marzo de 1827.

"En su consecuencia Su señoría usando de la misión que se le tiene conferida por S.M. otorga que vende y da en venta real a censo los cuartos de La Parrilla y Castillo de Otiñar y que hasta la presente han correspondido en posesión y propiedad a los caudales de propios de esta ciudad que da principio el de La Parrilla por la parte del sur en el rio de Otiñar, al mojón que hay en la falda de la última Escaleruela, sigue el Calar arriba y descabeza por lo alto al Barranco de lo Neveros; estando en ese sitio y mirando al norte sigue la cuerda adelante por la parte de poniente hasta llegar al Puntal de Navaltrillo y a la vereda real donde concluye ese cortado y desde el mismo hacia levante toma para la del norte la vereda real abajo a buscar la linde de Puerto Blanco y mirando al sur hacia levante continua por la cerca de Casablanca desdenciendo al rio hasta el Carcajar donde confluyen los linderos, atravesándolo el camino que de esta ciudad se dirige a la de Granada... Y el del Castillo principia en el primer mojón que hay a la falda de la expresada última Escaleruela, continuando agua arriba a la peña de la Bríncola siguiendo la cimbra adelanta al Portillo del Frayle y a la Cañada de las Azadillas y por la parte de levante sale desde la expresada cañada hasta el Collado del Cerro de las Nogueras, continuando la cimbra al puntal de la de la Fuente de los Ballesteros y falda de la Cimbra de los Madroñales a descender al rio; por la parte del sur sale de este al Peñón del Sombrero, al Pollo del Gallego hasta el ¿Artesón? de Senda Nueva; rodeándose al norte sigue la linde de Peña Blanca y se deja caer al Cerrillo de los Caracoles, desde cuyo sitio sube al Puntal de la Mata continuando la cuerda adelante hasta dar vista al Barranco de los Neveros que lo divide con el citado de La Parrilla; desde dicho barranco por la parte de levante va a parar al Puntal de la Matilla y sigue la vertiente de esta a brincar el Puerto de la Lagunillas por el canal abajo a juntarse con el mojón donde se fundaron, hasta el rio, en que se concluye el deslinde del citado cuarto."

Fig. 4. Documento de caracterización general del área de estudio. Apartados informativos. 


\section{PROYECTO OTIÑAR}

\begin{tabular}{|ll|l|}
\hline ACTUACIÓN: & Reconocimiento de Límites & Cad \\
\hline DOCUMENTO: & Límites de Señorío & Cod \\
\hline
\end{tabular}

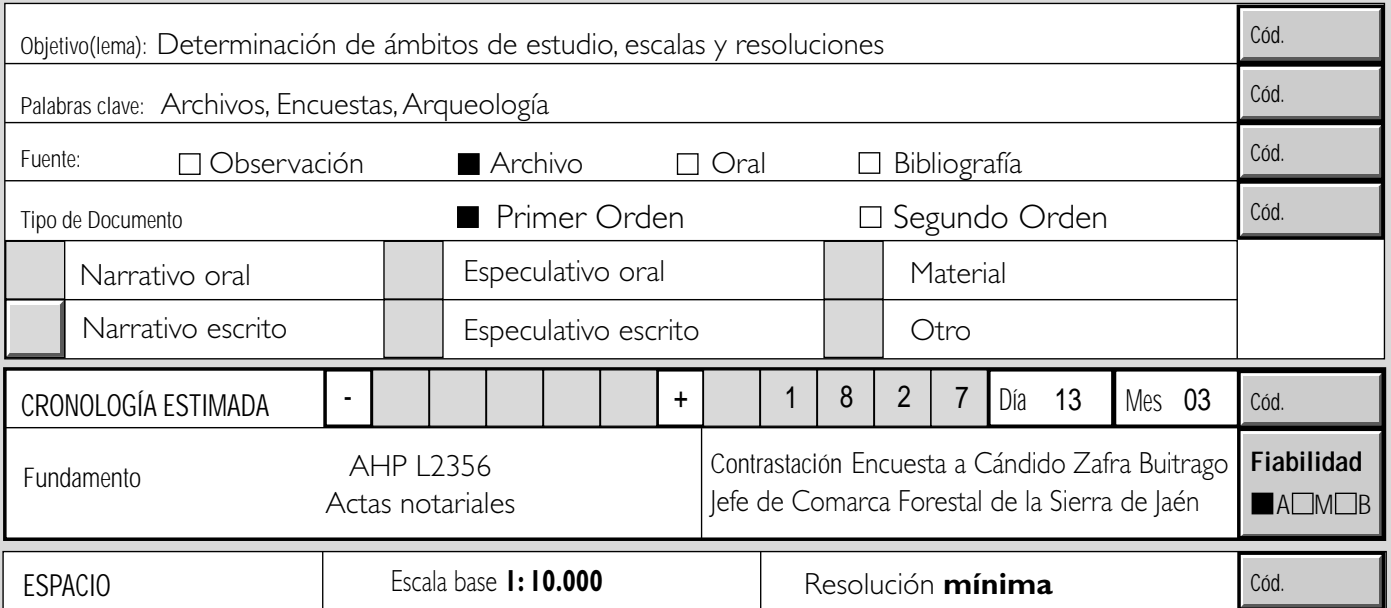

Sistemas relacionados Vías de comunicación, Red hídrica, Red hidrológica, vegetación, patrones de asentamiento, Fundación.

\begin{tabular}{|l|l|l|l|}
\hline \hline \multicolumn{2}{|l|}{ Antecedentes Documentales } & Documentos Derivados \\
\hline Cód. Doc.: Escritura de venta a censo & & Cód. Doc.: & \\
\hline Cód. Doc.: Mapa I: 10.000 & 1001 & Cód. Doc.: & \\
\hline Cód. Doc.: Mapa I: 5.000 & 1002 & Cód. Doc.: & \\
\hline Cód. Doc.: & & Cód. Doc.: & \\
\hline
\end{tabular}

\section{OBSERVACIONES}

La voz "Santa Cristina" del Diccionario de Madoz recoge los siguientes límites:

"Confina al N. con las Alcandoras y Peña de la Bríncola; E. la cumbre llamada el Cobarrón; S. Cerro de las Matas, y O. el Puerto del Victor". Se equivoca en la orientación y en los límites que según Cándido Zafra Buitrago eran, antes de la venta de la Parrilla efectuada en los años 80 de este siglo, los siguientes: Al Norte el cerro del Rajón, el cerro del Frontón y la desembocadura del arroyo de la Parrilla en el rio Quiebrajano; al Este la Bríncola, el portillo del Pinar, la Naríz del Puntal del Fraile, la Pasada de los Carboneros en la carretera de la Cañada de las Hazadillas y el Puntal de Acebuchal; al Sur el cerro del Aguilón del Pollo del Gallego, el cerro de Peña Blanca y el cerro Caracoles; al Oeste sigue el límite del término municipal de Jaén, entre el Puntalón de la Matilla, el Cerro de la Matilla y Navatrillo. Conicidiendo con los fijados en las escrituras. Falta ubicar los mojones.

\begin{tabular}{|c|c|c|c|c|c|c|c|}
\hline \multicolumn{3}{|c|}{ Fecha Observación I 5/0 | /95 } & \multicolumn{3}{|c|}{ Fecha Registro I | /02/97 } & \multicolumn{2}{|c|}{ Fecha Codificación } \\
\hline \multicolumn{3}{|c|}{ Autor Narciso Zafra de la Torre } & \multicolumn{3}{|c|}{ Narciso Zafra de la Torre } & \multicolumn{2}{|l|}{ Autor } \\
\hline \multicolumn{2}{|c|}{ Fecha Revisión } & \multicolumn{2}{|l|}{ Fecha Revisión } & \multicolumn{2}{|c|}{ Fecha Revisión } & \multicolumn{2}{|c|}{ Fecha Revisión } \\
\hline \multicolumn{2}{|l|}{ Autor } & \multicolumn{2}{|l|}{ Autor } & \multicolumn{2}{|l|}{ Autor } & \multicolumn{2}{|l|}{ Autor } \\
\hline Documento & Cód. & Documento & Cód. & Documento & Cód. & Documento & Cód. \\
\hline
\end{tabular}

Fig. 5. Documento de caracterización general del área de estudio. Apartados relacionales. 


\section{PROYECTO OTIÑAR}

\begin{tabular}{|ll|l|}
\hline ACTUACIÓN: & Reconocimiento de actividad agraria & Cód. \\
\hline DOCUMENTO: & Barranco de la Tinaja & Cód. \\
\hline
\end{tabular}

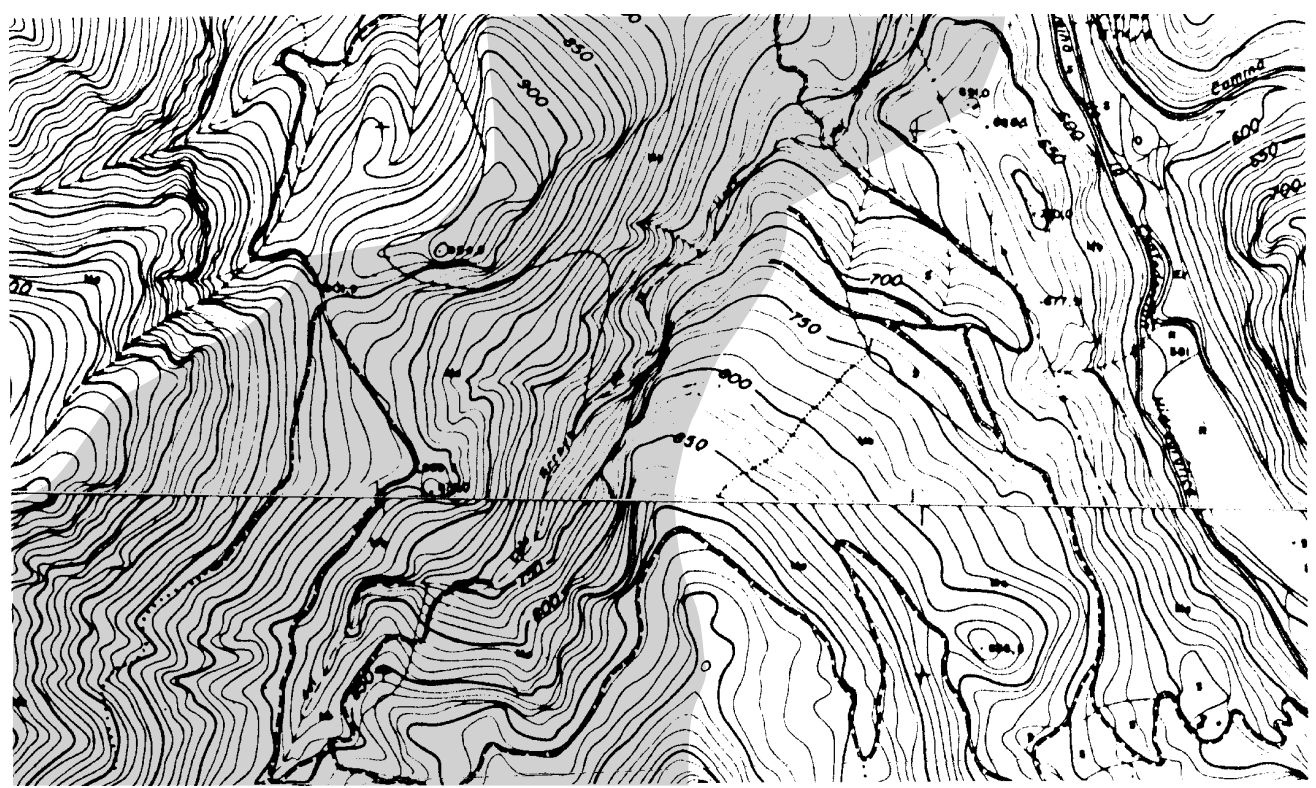

No hay cultivos y no hay evidencias de su presencia en el pasado, sin embargo hay un aprovechamiento humano importante: El paisaje puede organizarse en dos ámbitos uno "bajo", en altitud y en su posición en relación con el arroyo, dominado por cornicabras, acebuches, majuelos y,en menor medida, agracejos, almeces e higueras; y otro "alto" donde predomina el pinar, el monte bajo y manchas localizadas de bojes y quejigos. El contacto entre estos ámbitos podemos fijarlo en la Rinconada de las higueras. El aspecto "natural" del sitio se ve roto por determinados puntos "vacíos", que son notables en el curso bajo del arroyo por localizarse en poyos y anchuras. El efecto de la presión del ganado sobre la vegetación es evidente en algunos como el Poyo del Nicho donde los agracejos y acebuches (abundantes bajo él por inaccesibles) se limitan a su borde en una línea donde no es posible su aprovechamiento sin grave riesgo.

En la zona alta los claros se perciben en puntos de pendiente mas o menos moderada y con extensiones mucho mayores, sobre todo por el area limitada por el Peñón del Púlpito al oeste y el Peñón de Acerrocobo al este. Aquí se aprecia una gran calva en la que debe leerse la mano humana. El Peñón de Acerrocobo es un punto de estancia de ganado elegido por sus cualidades (abrigado, soleado, seguro y cercable). El monte bajo y el pinar que, por comparación con el entorno, debió existir, deja paso a un claro desprovisto de tierra o a lo sumo cubierto por matorral ralo, que ha sido creado por la acción conjunta del ganado y de los madereros (observese el amplio carril, no senda o vereda, que lo atraviesa), la pendiente, la lluvia y el sol han hecho el resto.

El bosque de pinos se encuentra cortado por dos carriles que llegan a la cabecera del barranco, uno al norte y otro al sur, construidos con amplitud y paratas de piedra pero sir firme añadido, indican una utilización puntual y su destino (el bosque) apuntan su uso para el desplazamiento de cargas con acémilas, carros o medios mecánicos. Los carriles se abren con la intención de acceder a los pinares para su corta y traslado. El pinar que hoy se ve es el resultado de ese aprovechamiento, los pinos mas viejos son los que en el momento de la última tala eran lo suficientemente pequeños para ser descartados, así el bosque que ahora crece es muy joven y no se debe leer en él ninguna evolución natural.

Al oeste del Peñón del Púlpito se observa otro claro, achacable esta vez al fuego. La zona afectada está en fase de regeneración sobre todo en las umbrías, pero ha sufrido una importante pérdida de suelo, principalmente por escorrentía y sin repoblación es muy dificil que se restaure.

Fig. 6. Documento de caracterización de actividad agraria. Apartados informativos. 


\section{PROYECTO OTIÑAR}

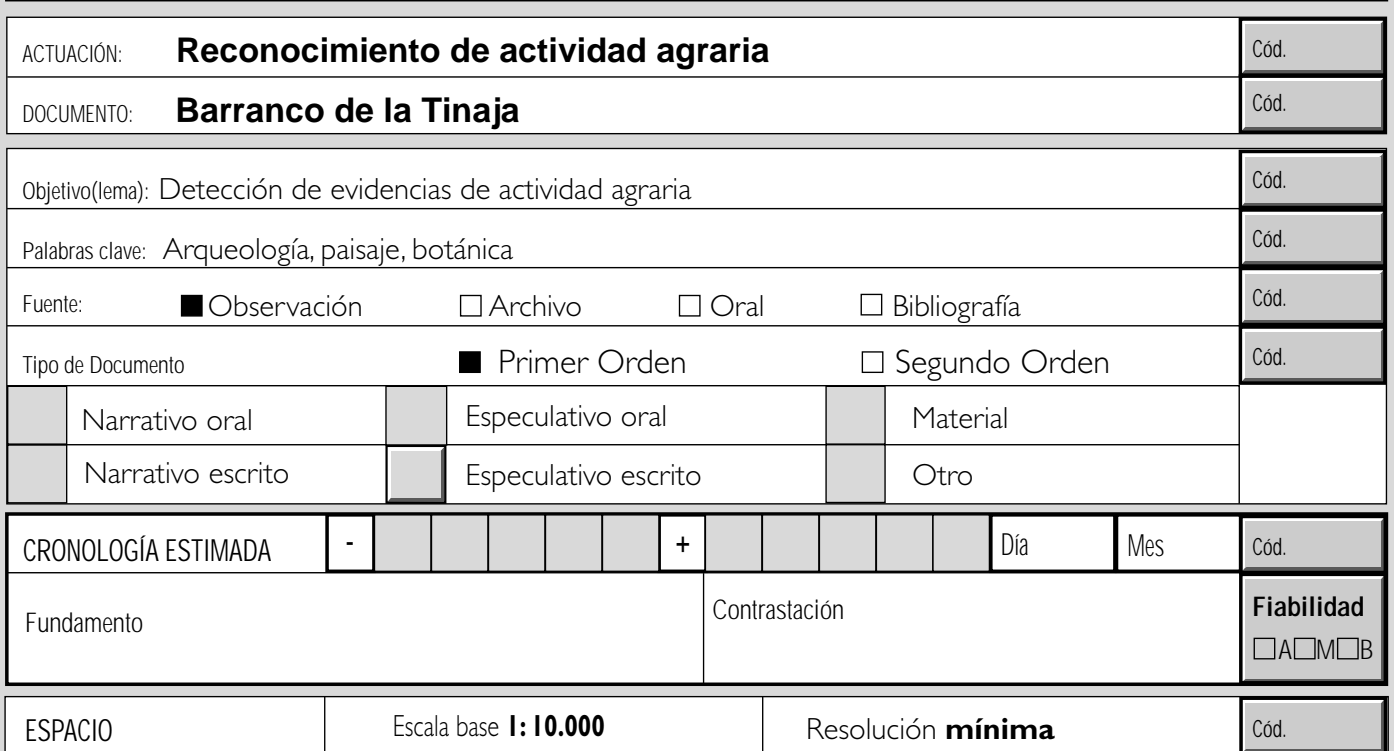

Sistemas relacionados Vías de comunicación, Red hídrica, parcelaciones ganaderas, vegetación de riberas

\begin{tabular}{|l|l|l|l|}
\hline \hline Antecedentes Documentales & Documentos Derivados \\
\hline Cód. Doc.: Escritura de venta a censo & $\mathbf{0 0 0 1}$ & Cód. Doc.: & \\
\hline Cód. Doc.: Mapa I: 10.000 & 1001 & Cód. Doc.: & \\
\hline Cód. Doc.: Mapa I: 5.000 & 1002 & Cód. Doc.: & \\
\hline Cód. Doc.: & Cód. Doc.: & \\
\hline
\end{tabular}

\section{OBSERVACIONES}

Útil en la demostración de que la presión sobre el territorio es primero una presión de las formas de propiedad y sus imposiciones y segundo una presión de la producción, más acelerada cuanto más mercantilizada. Para ello hay que demostrar que la presión sobre las mejores tierras para pastos (Hoyones y aledaños) del señorío era menor que la que soportaban el resto, rompiendo con la idea de un aprovechamiento óptimo o racional de los recursos.

Útil para aceptar que la explotación ganadera necesita de una parcelación del territorio que si bien no siempre deja huella, sí debe tenerse presente para comprender los distintos niveles de uso de cada terreno.

\begin{tabular}{|l|l|l|}
\hline Fecha Cbservación I 5/0 I/95 & Fecha Registro I I/02/97 & Fecha Codificación \\
\hline Autor Narciso Zafra de la Torre & Autor Narciso Zafra de la Torre & Autor \\
\hline
\end{tabular}

\begin{tabular}{|c|c|c|c|c|c|c|c|}
\hline \multicolumn{2}{|c|}{ Fecha Revisión } & \multicolumn{2}{|c|}{ Fecha Revisión } & \multicolumn{2}{|c|}{ Fecha Revisión } & \multicolumn{2}{|c|}{ Fecha Revisión } \\
\hline Autor & & Autor & & Autor & & Autor & \\
\hline Documento & Cód. & Documento & Cód. & Documento & Cód. & Documento & Cód. \\
\hline
\end{tabular}

Fig. 7. Documento de caracterización de actividad agraria. Apartados relacionales. 


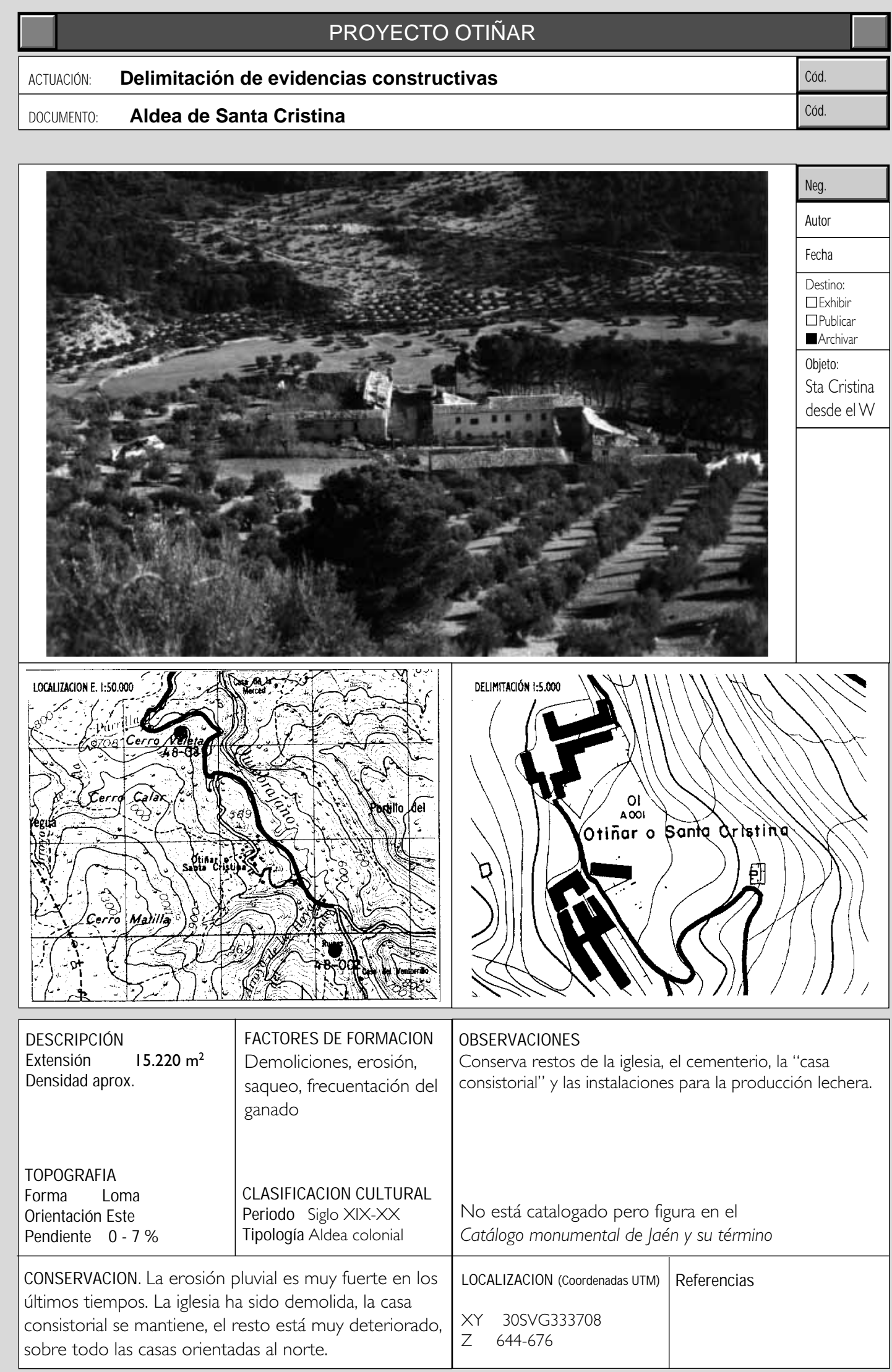

Fig. 8. Documento de caracterización de espacio construído. Apartados informativos. 


\section{PROYECTO OTIÑAR}

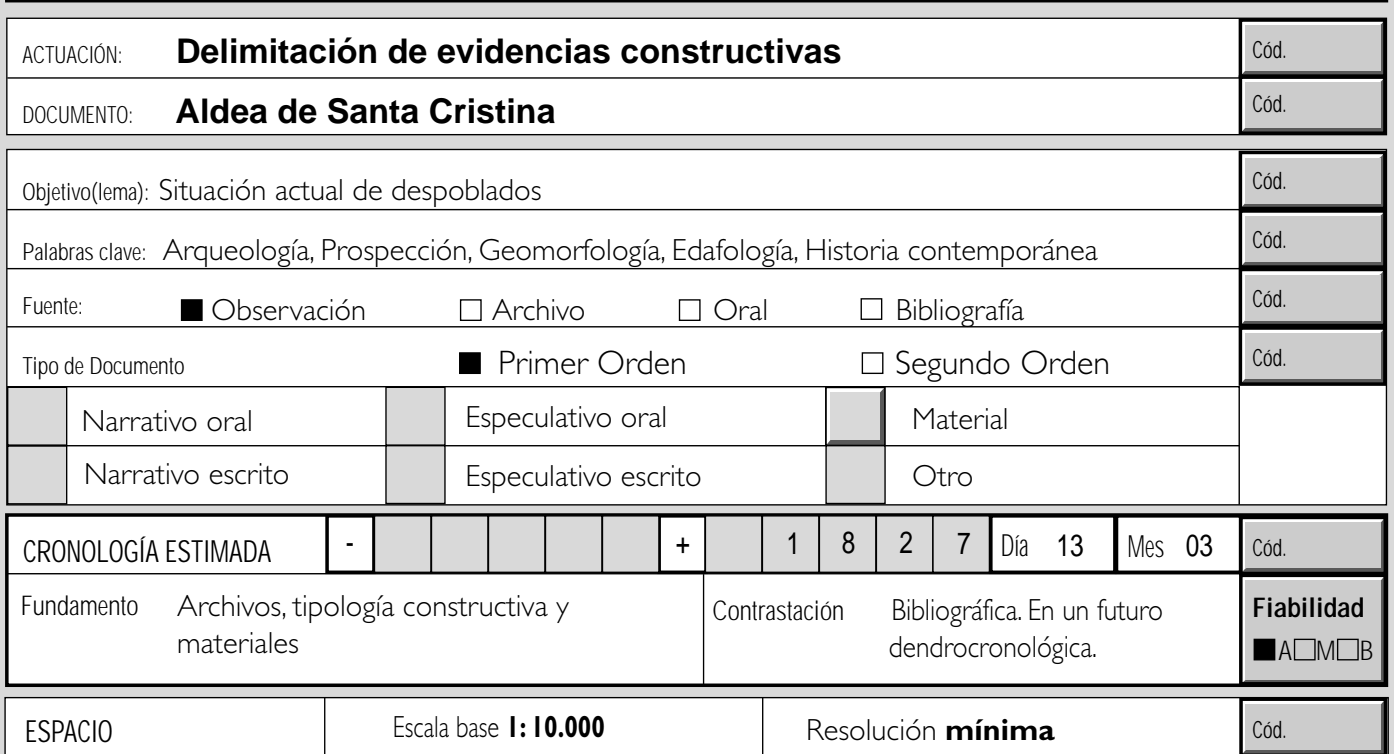

Sistemas relacionados

Poblamiento contemporáneo, vias de comunicación, sistemas constructivos.

\begin{tabular}{|l|l|l|l|}
\hline \hline Antecedentes Documentales & Documentos Derivados \\
\hline Cód. Doc.: Diccionario de Madoz (1850) & & Cód. Doc.: Plantas generales (2 alturas) & \\
\hline Cód. Doc.: Ortega Sagrista (1985) & & Cód. Doc:. Alzados (calles e instalaciones) & \\
\hline Cód. Doc.: Actas municipales |4//1//831 & & Cód. Doc.: Sección Plaza de las Mercedes & \\
\hline Cód. Doc.: López Pérez (1989) & & Cód. Doc:. ensayo "genealogía constructiva" & \\
\hline
\end{tabular}

\section{OBSERVACIONES}

Se pueden palpar las formas de vida tradicionales en las constucciones. La ausencia de determinados elementos imprescindibles al confort suponen un fuerte impacto. Por contra la presencia de otros hoy prescindibles y su peculiar construcción rompen esquemas muy asentados, hasta en las interpretaciones arqueológicas, sobre los mínimos exigibles para la ocupación ( v.g. distancia al agua o paredes de caña en el s. XX). Util a otro nivel para ilustrar los procesos deposicionales y postdeposicionales.

Se podría estudiar la reconstrucción de algunas viviendas y permitir la edificación de nuevas con cautelas estrictas en cuanto a imagen, disposición y tamaño, siempre en el marco de desarrollo de un plan global (una especie de estudio de detalle muy aquilatado).

La Plaza requeriría una repoblación, los álamos viejos, maltrechos y mermados enmascaran la disposición original.

\begin{tabular}{|l|l|l|}
\hline Fecha Observación 06/1995 & Fecha Registro I 0/02/1997 & Fecha Codificación \\
\hline Autor Narciso Zafra de la Torre & Autor Narciso Zafra de la Torre & Autor \\
\hline
\end{tabular}

\begin{tabular}{|c|c|c|c|c|c|c|c|}
\hline \multicolumn{2}{|c|}{ Fecha Revisión } & \multicolumn{2}{|c|}{ Fecha Revisión } & \multicolumn{2}{|c|}{ Fecha Revisión } & \multicolumn{2}{|c|}{ Fecha Revisión } \\
\hline \multicolumn{2}{|l|}{ Autor } & \multicolumn{2}{|l|}{ Autor } & \multicolumn{2}{|l|}{ Autor } & \multicolumn{2}{|l|}{ Autor } \\
\hline Documento & Cód. & Documento & Cód. & Documento & Cód. & Documento & Cód. \\
\hline
\end{tabular}

Fig. 9. Documento de caracterización de espacio construído. Apartados relacionales. 